\title{
Dipeptidyl Peptidase-4 Inhibitors and Inflammation: Dpp-4 Inhibitors Improve Mean Pleatelet Volume and Gamma Glutamyl Transferase Levels
}

\author{
Deniz Avcı \\ Department of Internal Medicine, Kayseri State Training and Research Hospital, Kayseri, Turkey \\ Email: denav38@gmail.com
}

How to cite this paper: Avc1, D. (2019) Dipeptidyl Peptidase-4 Inhibitors and Inflammation: Dpp-4 Inhibitors Improve Mean Pleatelet Volume and Gamma Glutamyl Transferase Levels. Journal of Biosciences and Medicines, 7, 42-53. https://doi.org/10.4236/jbm.2019.72004

Received: December 1, 2018

Accepted: January 21, 2019

Published: January 24, 2019

Copyright $\odot 2019$ by author(s) and Scientific Research Publishing Inc. This work is licensed under the Creative Commons Attribution International License (CC BY 4.0).

http://creativecommons.org/licenses/by/4.0/

\section{c. (i) Open Access}

\begin{abstract}
AIM: The purpose of this research was to determine the changes of the inflammatory parameters in the long term with the use of dipeptidyl peptidase-4 inhibitors. Material and Methods: In this research we have retrospectively reviewed the records of 80 patients who had added dipeptidyl peptidase- 4 inhibitors (40 sitagliptin and 40 vildagliptin) to their ongoing therapies. Patients' values of inflammation at the beginning of this process were taken as initial values, while values at the end of this process were considered as final values. Results: A total of 80 patients [38.8\% $(n=31)$ of the patients were male, while $61.3 \%(n=49)$ were female] enrolled in the study. When the whole group was evaluated, the mean age was $56.1 \pm 9.7$ years. The median follow-up time of the patients with DPP-4 inhibitors was 18 (2 - 64) months. The mean MPV value was measured as $8.79 \pm 1.71 \mathrm{fL}$ before DPP- 4 inhibitors and it was $10.06 \pm 1.42 \mathrm{fL}$ after the follow-up period ( $\mathrm{p}<0.001)$. The median value serum GGT was 30.5 (13 - 194) U/L before DPP-4 inhibitor and 29.5 $(12-112) \mathrm{U} / \mathrm{L}$ at the end $(\mathrm{p}=0.048)$. The mean uric acid level before the use of dipeptidyl peptidase- 4 inhibitors was $4.7 \pm 1.6 \mathrm{mg} / \mathrm{dL}$, and this level was $5.0 \pm 1.5 \mathrm{mg} / \mathrm{dL}$ after the follow-up period $(\mathrm{p}=0.048)$. Conclusion: In this study, it was observed that MPV and GGT levels were improved by dipeptidyl peptidase-4 inhibitors in long-term.
\end{abstract}

\section{Keywords}

DPP-4 Inhibitors, MPV, GGT, Inflammation, Diabetes Mellitus

\section{Introduction}

Diabetes mellitus is a global public concern with an increasing prevalence. In 
2014, World Health Organization (WHO) reported that 422 million adult diabetics were living worldwide [1]. In addition to regulating blood glucose, agents in current therapy are expected to have additional pleiotropic effects to help the prevention of diabetic macro and microvascular complications. Mechanisms of the relationship between incretins and complications of diabetes are now better understood [2]. There is now more evident accumulation of information about the effects of incretin-based therapies on the complications. The effects are not only through glycemic control, the pleotropic effects of these group agents such as anti-inflammatory features, and their effects on the vascular endothelium are also playing roles in the pathophysiology [3].

Dipeptidyl peptidase-4 (DPP-4) is a serine protease that cleaves the incretin hormones [4]. Genetically ablation of DPP-4 in mice and rats resulted in reduced insulin resistance [5] [6]. DPP-4 inhibitors were first used in 2006 in diabetes mellitus, and then they became the important part of the treatment of Type 2 Diabetes mellitus with various combinations [7] [8] [9] and new indications [10] [11] [12] [13].

Perhaps the worst aspect of diabetes is the systemic inflammation and oxidative stress and they are almost accused of being the real reasons underlying many complications of diabetes [14] [15] [16]. MPV is now well known as a predictor of inflammation and has been shown in many cases as a marker of inflammation [17] [18] [19]. In our previous research, we have shown that we can use MPV in the diagnosis of uveitis and venous thrombosis in patients with Behçet's syndrome [20] [21].

GGT (Gamma glutamyltransferase) is an enzyme present in the serum and on the surface of the membrane of many cells. GGT is an enzyme that catalyzes the first step of extracellular degradation of glutathione (an anti-oxidant). During this degradation, Low Density lipoprotein (LDL) is also oxidized and accumulates in the cell wall [22]. The degradation of glutathione also results in formation of peroxide free radicals [23].

In this research, the effects of the long-term use of DPP-4 inhibitors on certain inflammatory parameters [uric acid, GGT, MPV, platelet to lymphocyte ratio (PLR), neutrophil to lymphocyte ratio (NLR)] were studied.

\section{Materials and Methods}

The study was conducted by retrospectively reviewing the data of 80 patients who were followed in the diabetes clinic of the Kayseri education and research hospital between February 2012 and June 2016 whose treatments were supplemented with DPP-4 inhibitors (40 sitagliptin and 40 vildagliptin). All the patients were being managed by the author. The study was approved by Ethics Committee of Kayseri State Hospital. The day the patients started using DPP-4 inhibitors was determined as the first day and the day the patients were separated from the DPP-4 treatment, or the day when other agents (such as insulin and oral anti-diabetic agents) were added or removed from the therapy was considered as the last day. Hematological parameters such as MPV, PLR, NLR and 
biochemical parameters such as uric acid and GGT were used to monitor the inflammatory changes of the patients. Patients who were accused to have other inflammatory processes such as infection, chronic inflammatory diseases at times of admission were excluded from the study. Patient consent to review their medical records was not required by the Kayseri State Hospital Ethics Committee because of the retrospective nature of the research.

\section{Statistical Analyzes}

The Shapiro-Wilk test and histograms were used to test whether the data fit the normal distribution. The data with the normal distribution were expressed as mean \pm standard deviation, while the data without normal distribution are expressed as median (minimum-maximum). "Paired sample test" or "Wilcoxon signed ranks test" was used to compare the post-treatment values of the patients with DPP-4 inhibitor to those of the same patients with pre-use values, according to the normality of the distribution. Taking the distributions of the data into account, Pearson correlation test or spearman correlation test was used for correlation. $\mathrm{P}<0.050$ was considered statistically significant. All statistical analyses were conducted using SPSS software version 21 for windows, IBM Corporation, USA).

\section{Results}

A total of 80 diabetic patients were included in the study. One hundred grams of sitagliptin was initiated (once a day) to 40 of them, while vildagliptin $100 \mathrm{mg}$ was started in the other 40 patients (two divided doses per day).

When the whole group was evaluated, the mean age was $56.1 \pm 9.7$ years.38.8\% ( $n=31)$ of the patients were male, while $61.3 \%(n=49)$ were female. The mean age in the sitagliptin group was $56.3 \pm 8.2$ years, while it was $55.9 \pm 11.1$ years in vildagliptin group $(\mathrm{p}=0.855)($ Table 1$)$.

The median duration of diabetes was $5(0$ - 25) years. There was no statistically significant difference between the median diabetes-duration of vildagliptin [4 $(0-25)$ years $]$ and sitagliptin groups $[7(0-23)$ years $](p=0.759)$. The median

Table 1. Demographic characteristics, physical measurements of patients and group comparisons of these parameters are summarized in Table 1.

\begin{tabular}{ccccc}
\hline \multirow{2}{*}{ Variables } & Total group & \multicolumn{2}{c}{ Subgroups } & \multirow{2}{*}{$\mathrm{p}$} \\
\cline { 3 - 4 } & & Vildagliptin & Sitagliptin & \\
\hline Age (years) & $56.08 \pm 9.71$ & $55.88 \pm 11.1$ & $56.28 \pm 8.2$ & $\mathrm{p}=0.855$ \\
Waist $(\mathrm{cm})$ & $104.36 \pm 13.0$ & $104.4 \pm 13.1$ & $104.3 \pm 13.1$ & $\mathrm{p}=0.979$ \\
BMI $\left(\mathrm{kg} / \mathrm{m}^{2}\right)$ & $30.2 \pm 6.2$ & $33.5 \pm 6.6$ & $33.2 \pm 5.8$ & $\mathrm{p}=0.297$ \\
DM duration (years) & $5(0-25)$ & $4(0-25)$ & $7(0-23)$ & $\mathrm{p}=0.594$ \\
DPP-4 duration (months) & $18(2-64)$ & $25(3-64)$ & $10(2-58)$ & $\mathrm{p}=0.725$ \\
\hline
\end{tabular}

\#P values represent comparisons of vildagliptin and sitagliptin groups with each other. DPP-4 duration: DPP-4 inhibitor follow-up (months), BMI: Body Mass index. 
follow-up time of the patients with DPP-4 inhibitors was 18 (2 - 64) months. This value was 25 (3 - 64) months in vildagliptin group and $10(2-58)$ months in patients who were added sitagliptin $(\mathrm{p}=0.107)$.

There was a statistically significant difference between the initial MPV values of the patients using DPP- 4 inhibitors $(8.79 \pm 1.71 \mathrm{fL})$ and the values obtained at theend of the therapy $(10.06 \pm 1.42 \mathrm{fL})(\mathrm{p}<0.001)$.

The median serum GGT level was 30.5 (13 - 194) U/L before DPP-4 inhibitors and $29.5(12-112) \mathrm{U} / \mathrm{L}$ at the end $(\mathrm{p}=0.049)$.

The initial mean NLR was $1.98 \pm 0.79$ and $1.86 \pm 0.71$ at the end of the therapy $(\mathrm{p}=0.579)$.

The mean PLR value of the patients before the DPP-4 inhibitor therapy was $109.9 \pm 32.0$, which was finally calculated as $108.9 \pm 33.0(\mathrm{p}=0.892)$.

The mean uric acid level before the use of DPP-4 inhibitor was $4.7 \pm 1.6$ $\mathrm{mg} / \mathrm{dL}$, and this level was $5.0 \pm 1.5 \mathrm{mg} / \mathrm{dL}$ after the follow-up duration. This increase was statistically significant $(\mathrm{p}=0.048)$. Mean uric acid level in vildagliptin group was $4.6 \pm 1.2 \mathrm{mg} / \mathrm{dL}$ before treatment and $5.1 \pm 1.6 \mathrm{mg} / \mathrm{dL}$ after treatment $(\mathrm{p}=0.105)$. Mean uric acid level in sitagliptin group was $4.0 \pm 1.2 \mathrm{mg} / \mathrm{dL}$ before treatment and $4.3 \pm 1.1 \mathrm{mg} / \mathrm{dL}$ after treatment $(\mathrm{p}=0.310)$.

Comparisons of the inflammatory parameters before and after the treatment by DPP-4 inhibitors were summarized in Table 2 .

\section{Discussion}

The primary finding of this research was to demonstrate the improvements in inflammatory markers such as MPV and GGT by adding DPP-4 inhibitors (vildagliptin and sitagliptin) to various therapies of diabetics.

Systemic inflammation in diabetic patients is thought to be the underlying cause of many complications such as atherosclerosis [24] [25] [26]. It is believed that the treatment plan targeting inflammatory pathways will reduce the complications, especially the cardiovascular system complications [27] [28] [29]. One of the methods used in the treatment of diabetes is DPP-4 inhibition. Various publications have described the positive effects of DPP-4 inhibitors on some parameters that show inflammation [10] [30] [31]. There are also publications in

Table 2. Comparisons of the inflammatory parameters before and after the treatment by DPP-4 inhibitors.

\begin{tabular}{cccc}
\hline Variables & Before DPP-4 inhibitors & After DPP-4 inhibitors & $\mathrm{p}$ \\
\hline Uric acid (mg/dL) & $4.7 \pm 1.6$ & $5.0 \pm 1.5$ & 0.048 \\
NLR (ratio) & $1.98 \pm 0.79$ & $1.86 \pm 0.71$ & 0.579 \\
PLR (ratio) & $109.9 \pm 32.0$ & $108.9 \pm 33.0$ & 0.892 \\
MPV (fL) & $8.79 \pm 1.71$ & $10.06 \pm 1.42$ & $<0.001$ \\
GGT (U/L) & $30.5(13-194)$ & $29.5(12-112)$ & 0.049 \\
\hline
\end{tabular}

DPP-4: dipeptidyl peptidase-4, NLR: neutrophil to lymphocyte ratio, PLR: platelet to lymphocyte ratio, MPV: mean platelet volume, GGT: gamma glutamyltranspeptidase. 
which DPP-4 inhibitors reduce atheroembolic events [32]. Various publications describe the positive effects of DPP-4 inhibitors on inflammatory parameters. The results of our study do not coincide with the literature. This may be due to short follow-up periods in previous studies. In this study, we compared the values at the beginning and end of the treatment of patients who were followed up for a median of $18(2-64)$ months. In the majority of previous studies, a maximum of 6 months follow-up was used. We discussed the findings in separate sections below.

\subsection{MPV}

MPV plays a role as a negative acute phase marker in various inflammatory conditions [33]. In fact, studies have shown that no significant change in MPV levels is observed in diabetics, and MPV changes are more commonly attributed to diabetic complications [34] [35]. Depending on the use of the DPP-4 inhibitor, a change in a parameter such as MPV, an indicator for thrombosis and inflammation, may be considered significant in reflecting the inflammatory change in diabetic patients. In previous studies, the relationship between MPV and atherothrombosis in diabetics has been established [21] [36] [37] [38] [39]. That is, an improvement in MPV level may indicate an improvement in the cardiovascular mortality of diabetic patients. MPV has previously been investigated in patients using DPP-4 for this reason. Varım et al. showed a decrease in MPV levels in patients using DPP-4 inhibitor [40]. A follow-up of 6 months was made in this study. According to the results of our study, MPV values were increased statistically by using DPP-4 inhibitor. This result coincided with the atheroembolic studies in the literature [21] [36]. We thought that the contradictory results between the two studies might be related to patient selection. There was also a difference in follow-up periods between the two studies. In other words, the reversal of the athero-inflammatory characteristic of DPP-4 by DPP-4 inhibitors could be monitored by MPV. Moreover, it could be observed with an extremely cheap and routine test.

\subsection{GGT}

GGT is responsible for the extracellular degradation of the antioxidant glutathione, resulting in reactive oxygen radicals [41]. Increased levels of GGT have been shown to be associated with subclinic inflammation [42], CVS and metabolic diseases [43] [44]. It has been shown that cyclosporine hepatotoxicity is less in vildagliptin-given rats and has a positive effect on serum GGT [45]. In a Japanese study of type 1 diabetes, the correlation between DPP-4 activity and serum GGT was noted. Again, in the same study, GGT has been mentioned as an independent risk factor for DPP-4 activity [46]. GLP-1 receptors have been shown in many cells as well as in hepatocytes [47]. In other words, the use of DPP-4 inhibitors was expected to have a positive effect on liver function [12]. In diabetic patients with NAFLD diagnosis, the use of DPP-4 inhibitor has been 
shown to cause a decrease in NAFDL [48]. In the study of Kanazawa et al., DPP-4 inhibitor use was associated with improvement in liver function in patients with liver damage, however, no statistically significant improvement was observed in normal liver function patients. There was no significant change in serum GGT in both groups [12]. In our study, we showed that the serum GGT level, an independent risk factor for cardiometabolic diseases, was significantly reduced following the use of DPP-4 inhibitor. The beneficial effects of DPP-4 inhibitor drugs on GGT, an independent risk factor for cardiometabolic diseases, can be considered as advantages of these drugs. We think the difference in our study is related to our long follow-up.

\subsection{Uric Acid}

Serum uric acid level is causally related to many inflammatory conditions [49] [50]. There is literature information that the use of DPP-4 inhibitor also reduces the uric acid level. Linagliptin has been reported to partially inhibit xanthine oxidase, thereby lowering serum uric acid [51]. Teneligliptin reduced uric acid levels by inhibiting xanthine oxidase in male rats [52]. In a study conducted by Shimodaira et al., vildagliptin has been reported to have a beneficial effect on serum uric acid [53]. In our study, serum uric acid was found to be statistically significant at amild level after administration of DPP-4 inhibitor. When vildagliptin and sitagliptin were studied separately, these significant results were not seen. Although there are not enough numbers, the contribution of these two drugs has been seen. This contradiction to the literature may have been caused by the inadequate number of cases or long follow-up periods.

\section{Limitations}

1) The socio-demographic characteristics of the patients were limited due to the retrospective design of the study.

2) A control group could not be standardized due to the retrospective nature and the design of the study.

\section{Conclusion}

DPP4 inhibitors have positive effects on systemic inflammation as well as diabetes mellitus regulation. In this study, we demonstrated these effects with another aspect for the first time by reporting MPV and GGT levels were positively affected by the use of DPP-4 inhibitors. In addition, we could not see the lowering effect of DPP-4 inhibitors on the uric acid levels mentioned in the literature. These differences in the results might be due to patient selections and the length of the follow-up durations. Future researches are needed to confirm these results and clarify these dilemmas.

\section{Funding}

This research received no specific grant from any funding agency in the com- 
mercial, public or not-for-profit sectors.

\section{Conflicts of Interest}

The author declares that there is no conflict of interest.

\section{References}

[1] WHO (2017) Global Report on Diabetes. World Health Organization. https://www.who.int/diabetes/global-report/en/

[2] Kang, Y.M. and Jung, C.H. (2017) Effects of Incretin-Based Therapies on Diabetic Microvascular Complications. Endocrinology and Metabolism, 32, 316-325. https://synapse.koreamed.org/DOIx.php?id=10.3803/EnM.2017.32.3.316 https://doi.org/10.3803/EnM.2017.32.3.316

[3] Kang, Y.M. and Jung, C.H. (2016) Cardiovascular Effects of Glucagon-Like Peptide-1 Receptor Agonists. Endocrinology and Metabolism, 31, 258-274.

http://synapse.koreamed.org/DOIx.php?id=10.3803/EnM.2016.31.2.258 https://doi.org/10.3803/EnM.2016.31.2.258

[4] Pratley, R.E. and Gilbert, M. (2008) Targeting Incretins in Type 2 Diabetes: Role of GLP-1 Receptor Agonists and DPP-4 Inhibitors. The Review of Diabetic Studies, 5, 73-94. https://doi.org/10.1900/RDS.2008.5.73 http://www.soc-bdr.org/content/e4/e887/volRdsVolumes5237/issRdsIssues5874/ch pRdsChapters5886/strRdsArticles5887/index_en.html?preview=preview

[5] Conarello, S.L., Li, Z., Ronan, J., Roy, R.S., Zhu, L., Jiang, G., et al. (2003) Mice Lacking Dipeptidyl Peptidase IV Are Protected against Obesity and Insulin Resistance. Proceedings National Academy of Sciencs of the USA, 100, 6825-6830. http://www.pnas.org/cgi/doi/10.1073/pnas.0631828100 https://doi.org/10.1073/pnas.0631828100

[6] Ben-Shlomo, S., Ben, S.S., Zvibel, I., Rabinowich, L., Goldiner, I., Shlomai, A., et al. (2013) Dipeptidyl Peptidase 4-Deficient Rats Have Improved Bile Secretory Function in High Fat Diet-Induced Steatosis. Digestive Diseases and Sciences, 58, 172-178. http://link.springer.com/10.1007/s10620-012-2353-7 https://doi.org/10.1007/s10620-012-2455-2

[7] Chen, C., Yu, Q., Zhang, S., Yang, P. and Wang, C.-Y. (2015) Assessing the Efficacy and Safety of Combined DPP-4 Inhibitor and Insulin Treatment in Patients with Type 2 Diabetes: A Meta-Analysis. International Journal of Clinical \& Experimental Pathology, 8, 14141-14150.

https://www.ncbi.nlm.nih.gov/pmc/articles/PMC4713513/

[8] DeFronzo, R., Triplitt, E. and Cersosimo, R.A. (2010) Pioglitazone and Alogliptin Combination Therapy in Type 2 Diabetes: A Pathophysiologically Sound Treatment. Vascular Health and Risk Management, 6, 671-690.

http://www.dovepress.com/pioglitazone-and-alogliptin-combination-therapy-in-ty pe-2-diabetes-a-p-peer-reviewed-article-VHRM https://doi.org/10.2147/VHRM.S4852

[9] Ahren, B. (2008) Novel Combination Treatment of Type 2 Diabetes DPP-4 Inhibition + Metformin. Vascular Health and Risk Management, 4, 383-394.

https://www.dovepress.com/novel-combination-treatment-of-type-2-diabetes-dpp4-inhibition--metfo-peer-reviewed-article-VHRM https://doi.org/10.2147/VHRM.S1944

[10] Sa-Nguanmoo, P., Tanajak, P., Kerdphoo, S., Jaiwongkam, T., Pratchayasakul, W., 
Chattipakorn, N., et al. (2017) SGLT2-Inhibitor and DPP-4 Inhibitor Improve Brain Function via Attenuating Mitochondrial Dysfunction, Insulin Resistance, Inflammation, and Apoptosis in HFD-Induced Obese Rats. Toxicology and Applied Pharmacology, 333, 43-50. https://doi.org/10.1016/j.taap.2017.08.005 https://linkinghub.elsevier.com/retrieve/pii/S0041008X1730340X

[11] Wang, M.-T., Lin, S.-C., Tang, P.-L., Hung, W.-T., Cheng, C.-C., Yang, J.-S., et al. (2017) The Impact of DPP-4 Inhibitors on Long-Term Survival among Diabetic Patients after First Acute Myocardial Infarction. Cardiovasc Diabetol, 16, 89. http://cardiab.biomedcentral.com/articles/10.1186/s12933-017-0572-0 https://doi.org/10.1186/s12933-017-0572-0

[12] Kanazawa, I., Tanaka, K. and Sugimoto, T. (2014) DPP-4 Inhibitors Improve Liver Dysfunction in Type 2 Diabetes Mellitus. Medical Science Monit, 20, 1662-1667.

http://www.ncbi.nlm.nih.gov/pubmed/25228119 https://doi.org/10.12659/MSM.890989

[13] Angelopoulou, E. and Piperi, C. (2018) DPP-4 Inhibitors: A Promising Therapeutic Approach against Alzheimer's Disease. Annals of Translational Medicine, 6, 255-255. http://atm.amegroups.com/article/view/19330/19961 https://doi.org/10.21037/atm.2018.04.41

[14] Muriach, M., Flores-Bellver, M., Romero, F.J. and Barcia, J.M. (2014) Diabetes and the Brain: Oxidative Stress, Inflammation, and Autophagy. Oxidative Medicine and Cellular Longevity, 2014, Article ID 102158. https://doi.org/10.1155/2014/102158 http://www.ncbi.nlm.nih.gov/pubmed/25215171

[15] El Assar, M., Angulo, J. and Rodríguez-Mañas, L. (2016) Diabetes and Ageing-Induced Vascular Inflammation. The Journal of Physiology, 594, 2125-2146.

http://www.ncbi.nlm.nih.gov/pubmed/26435167 https://doi.org/10.1113/JP270841

[16] Karam, B.S., Chavez-Moreno, A., Koh, W., Akar, J.G. and Akar, F.G. (2017) Oxidative Stress and İnflammation as Central Mediators of Atrial Fibrillation in Obesity and Diabetes. Cardiovascular Diabetology, 16, 120.

http://www.ncbi.nlm.nih.gov/pubmed/28962617

https://doi.org/10.1186/s12933-017-0604-9

[17] Delgado-García, G., Galarza-Delgado, D.Á., Colunga-Pedraza, I., Borjas-Almaguer, O.D., Mandujano-Cruz, I., Benavides-Salgado, D., et al. (2016) O volume plaquetário médio está reduzido em adultos com lúpus ativo. Revista Brasileira de Reumatologia, 56, 504-508. http://www.ncbi.nlm.nih.gov/pubmed/26968762 https://doi.org/10.1016/j.rbr.2015.12.003

[18] Karaman, H., Karakukcu, C. and Kocer, D. (2013) Can Mean Platelet Volume Serve as a Marker for Prostatitis? International Journal of Medical Sciences, 10, 1387-1391. http://www.ncbi.nlm.nih.gov/pubmed/23983600 https://doi.org/10.7150/ijms.6126

[19] Beyazit, F., Öztürk, F.H., Pek, E. and Ünsal, M.A. (2017) Evaluation of the Hematologic System as a Marker of Subclinical İnflammation in Hyperemesis Gravidarum: A Case Control Study. Ginekologia Polska, 88, 315-319.

http://www.ncbi.nlm.nih.gov/pubmed/28727131 https://doi.org/10.5603/GP.a2017.0059

[20] Avci, A., Avci, D., Erden, F., Ragip, E., Cetinkaya, A., Ozyurt, K., et al. (2017) Can We Use the Neutrophil-to-Lymphocyte Ratio, Platelet-to-Lymphocyte Ratio, and Mean Platelet Volume Values for the Diagnosis of Anterior Uveitis in Patients with Behcet's Disease? Therapeutics and Clinical Risk Management, 13, 881. https://www.ncbi.nlm.nih.gov/pmc/articles/PMC5529084/ 
https://doi.org/10.2147/TCRM.S135260

[21] Erden, F., Karagoz, H., Avci, A., Avci, D., Cetinkaya, A. and Erden, A. (2017) The Values of Mean Platelet Volume and the Mean Platelet Volume/Platelet Ratio for Predicting Deep Venous Thrombosis in Behçet's Disease. LaboratoriumsMedizin, 41, 153-157. https://doi.org/10.1515/labmed-2017-0068 http://www.degruyter.com/view/j/labm.2017.41.issue-3/labmed-2017-0068/labmed2017-0068.xml

[22] Paolicchi, A., Minotti, G., Tonarelli, P., Tongiani, R., De Cesare, D., Mezzetti, A., et al. (1999) Gamma-Glutamyl Transpeptidase-Dependent İron Reduction and LDL Oxidation-A Potential Mechanism in Atherosclerosis. Journal of Investigative Medicine, 47, 151-160. http://www.ncbi.nlm.nih.gov/pubmed/10198571

[23] Kim, J.G., Chang, K., Choo, E.H., Lee, J.-M. and Seung, K.-B. (2018) Serum Gamma-Glutamyl Transferase İs a Predictor of Mortality in Patients with Acute Myocardial İnfarction. Medicine (Baltimore), 97, e11393.

http://www.ncbi.nlm.nih.gov/pubmed/30024510 https://doi.org/10.1097/MD.0000000000011393

[24] Williams, M.D. and Nadler, J.L. (2007) Inflammatory Mechanisms of Diabetic Complications. Current Diabetes Reports, 7, 242-248.

http://www.ncbi.nlm.nih.gov/pubmed/17547842 https://doi.org/10.1007/s11892-007-0038-y

[25] Akoumianakis, I. and Antoniades, C. (2017) Dipeptidyl Peptidase IV İnhibitors as Novel Regulators of Vascular Disease. Vascular Pharmacology, 96-98, 1-4. https://linkinghub.elsevier.com/retrieve/pii/S1537189117301556 https://doi.org/10.1016/j.vph.2017.07.001

[26] Duan, L., Rao, X., Xia, C., Rajagopalan, S. and Zhong, J. (2017) The Regulatory Role of DPP4 in Atherosclerotic Disease. Cardiovascular Diabetology, 16, 76. http://cardiab.biomedcentral.com/articles/10.1186/s12933-017-0558-y https://doi.org/10.1186/s12933-017-0558-y

[27] Lontchi-Yimagou, E., Sobngwi, E., Matsha, T.E. and Kengne, A.P. (2013) Diabetes Mellitus and İnflammation. Current Diabetes Reports, 13, 435-444.

http://link.springer.com/10.1007/s11892-013-0375-y https://doi.org/10.1007/s11892-013-0375-y

[28] Xie, W., Song, X. and Liu, Z. (2018) Impact of Dipeptidyl-Peptidase 4 İnhibitors on Cardiovascular Diseases. Vascular Pharmacology, 109, 17-26.

https:/linkinghub.elsevier.com/retrieve/pii/S1537189117302999 https://doi.org/10.1016/j.vph.2018.05.010

[29] Birnbaum, Y., Bajaj, M., Yang, H.-C. and Ye, Y. (2018) Combined SGLT2 and DPP4 Inhibition Reduces the Activation of the Nlrp3/ASC Inflammasome and Attenuates the Development of Diabetic Nephropathy in Mice with Type 2 Diabetes. Cardiovascular Drugs and Therapy, 32, 135-145.

http://link.springer.com/10.1007/s10557-018-6778-x https://doi.org/10.1007/s10557-018-6778-x

[30] Ikedo, T., Minami, M., Kataoka, H., Hayashi, K., Nagata, M., Fujikawa, R., et al. (2017) Dipeptidyl Peptidase-4 Inhibitor Anagliptin Prevents Intracranial Aneurysm Growth by Suppressing Macrophage Infiltration and Activation. Journal of the American Heart Association, 6. https://doi.org/10.1161/JAHA.116.004777 https://www.ahajournals.org/doi/10.1161/JAHA.116.004777

[31] Ervinna, N., Mita, T., Yasunari, E., Azuma, K., Tanaka, R., Fujimura, S., et al. (2013) Anagliptin, a DPP-4 İnhibitor, Suppresses Proliferation of Vascular Smooth 
Muscles and Monocyte İnflammatory Reaction and Attenuates Atherosclerosis in Male Apo E-Deficient Mice. Endocrinology, 154, 1260-1270.

https://academic.oup.com/endo/article-lookup/doi/10.1210/en.2012-1855 https://doi.org/10.1210/en.2012-1855

[32] Singh, T.P., Vangaveti, V.N. and Malabu, U.H. (2015) Dipeptidyl Peptidase-4 Inhibitors and Their Potential Role in the Management of Atherosclerosis-A Review. Diabetology \& Metabolic Syndrome, 9, 223-229.

https://linkinghub.elsevier.com/retrieve/pii/S1871402115000338

https://doi.org/10.1016/j.dsx.2015.04.005

[33] Tanju, C., Ekrem, G., Berksoy Emel, A. and Nur, A. (2014) Mean Platelet Volume as a Negative Marker of İnflammation in Children with Rotavirus Gastroenteritis. Iranian Journal of Pediatrics, 24, 617-622.

http://www.ncbi.nlm.nih.gov/pubmed/25793071

[34] Kodiatte, T.A., Manikyam, U.K., Rao, S.B., Jagadish, T.M., Reddy, M., Lingaiah, H.K.M., et al. (2012) Mean Platelet Volume in Type 2 Diabetes Mellitus. Journal of Laboratory Physicians, 4, 5-9. http://www.jlponline.org/text.asp?2012/4/1/5/98662 https://doi.org/10.4103/0974-2727.98662

[35] Papanas, N., Symeonidis, G., Maltezos, E., Mavridis, G., Karavageli, E., Vosnakidis, T., et al. (2004) Mean Platelet Volume in Patients with Type 2 Diabetes Mellitus. Platelets, 15, 475-458. https://doi.org/10.1080/0953710042000267707 http://www.tandfonline.com/doi/full/10.1080/0953710042000267707

[36] Aksu, E., Avci, D. and Cikim, G. (2016) The Relation between Mean Platelet Volume and Coronary Artery Disease in Type 2 Diabetes Mellitus Patients. International Journal of Health Sciences and Research, 6, 50. http://www.ijhsr.org

[37] Hudzik, B., Korzonek-Szlacheta, I., Szkodziński, J., Liszka, R., Lekston, A., Zubelewicz-Szkodzińska, B., et al. (2018) Association between Multimorbidity and Mean Platelet Volume in Diabetic Patients with Acute Myocardial İnfarction. Acta Diabetologica, 55, 175-183. http://link.springer.com/10.1007/s00592-017-1079-6 https://doi.org/10.1007/s00592-017-1079-6

[38] Sarikaya, S., Sahin, S., Akyol, L., Borekci, E., Yilmaz, Y.K., Altunkas, F., et al. (2014) Mean Platelet Volume İs Associated with Myocardial Perfusion Defect in Diabetic Patients. Cardiovascular Journal of Africa, 25, 110-113.

http://www.cvja.co.za/onlinejournal/vol25/vol25_issue3/\#20/z https://doi.org/10.5830/CVJA-2014-013

[39] Ulutas, K.T., Dokuyucu, R., Sefil, F., Yengil, E., Sumbul, A.T., Rizaoglu, H., et al. (2014) Evaluation of Mean Platelet Volume in Patients with Type 2 Diabetes Mellitus and Blood Glucose Regulation: A Marker for Atherosclerosis? International Journal of Clinical and Experimental Medicine, 7, 955-961. http://www.ncbi.nlm.nih.gov/pubmed/24955167

[40] Ceyhun, V.A.R.I.M., et al. (2015) Yeni Tanı Tip 2 Diabetes Mellitus' lu hastalarda DPP-4 inhibitörlerinin HbA1c, Hematolojik ve İnflamasyon Parametreleri Üzerine Etkileri. Ortadogu Medical Journal, 7, 172-177.

https://web.a.ebscohost.com/abstract?direct=true\&profile=ehost\&scope=site\&autht ype $=$ crawler\&jrnl=13093630\&AN=112699282\&h=rfRulFY0B7CU1J8CQsSO6WI11 pDAl7p70IYfyBQpSyUAbeFELlAFuPWCeO3B82ybfTxztGdZ\%2FKNT6lihdy7Ayg \%3D\%3D\&crl=c\&resultNs=AdminWebAuth\&resultLocal

[41] Goldberg, D.M. (1980) Structural, Functional, and Clinical Aspects of Gamma-Glutamyltransferase. CRC Critical Reviews in Clinical Laboratory Sciences, 12, 1-58. http://www.ncbi.nlm.nih.gov/pubmed/6104563 https://doi.org/10.3109/10408368009108725 
[42] Ali, S.S., Oni, E.T., Blaha, M.J., Veledar, E., Feiz, H.R., Feldman, T., et al. (2016) Elevated Gamma-Glutamyl Transferase İs Associated with Subclinical İnflammation İndependent of Cardiometabolic Risk Factors in an Asymptomatic Population: A Cross-Sectional Study. Nutrition \& Metabolism, 13, 37. http://www.ncbi.nlm.nih.gov/pubmed/27195017 https://doi.org/10.1186/s12986-016-0097-7

[43] Lee, D.S., Evans, J.C., Robins, S.J., Wilson, P.W., Albano, I., Fox, C.S., et al. (2007) Gamma Glutamyl Transferase and Metabolic Syndrome, Cardiovascular Disease, and Mortality Risk: The Framingham Heart Study. Arteriosclerosis, Thrombosis, and Vascular Biology, 27, 127-133.

https://doi.org/10.1161/01.ATV.0000251993.20372.40 https://www.ahajournals.org/doi/10.1161/01.ATV.0000251993.20372.40

[44] Ortakoyluoglu, A., Boz, B., Dizdar, O.S., Avc1, D., Cetinkaya, A. and Baspinar, O. (2016) The Association of Serum Gamma-Glutamyl Transpeptidase Level and Other Laboratory Parameters with Blood Pressure in Hypertensive Patients under Ambulatory Blood Pressure Monitoring. Therapeutics and Clinical Risk Management, 12, 1395-1401. https://doi.org/10.2147/TCRM.S116603

https://www.dovepress.com/the-association-of-serum-gamma-glutamyl-transpeptid ase-level-and-other-peer-reviewed-article-TCRM

[45] El-Sherbeeny, N.A. and Nader, M.A. (2016) The Protective Effect of Vildagliptin in Chronic Experimental Cyclosporine A-İnduced Hepatotoxicity. Canadian Journal of Physiology and Pharmacology, 94, 251-256.

http://www.nrcresearchpress.com/doi/10.1139/cjpp-2015-0336 https://doi.org/10.1139/cjpp-2015-0336

[46] Osawa, S., Kawamori, D., Katakami, N., Takahara, M., Sakamoto, F., Katsura, T., et al. (2016) Significant Elevation of Serum Dipeptidyl Peptidase-4 Activity in Young-Adult Type 1 Diabetes. Diabetes Research and Clinical Practice, 113, 135-142. https://doi.org/10.1016/j.diabres.2015.12.022 https://linkinghub.elsevier.com/retrieve/pii/S0168822716000309

[47] Gupta, N.A., Mells, J., Dunham, R.M., Grakoui, A., Handy, J., Saxena, N.K., et al. (2010) Glucagon-Like Peptide-1 Receptor İs Present on Human Hepatocytes and Has a Direct Role in Decreasing Hepatic Steatosis in Vitro by Modulating Elements of the İnsulin Signaling Pathway. Hepatology, 51, 1584-1592.

https://doi.org/10.1002/hep.23569

[48] Yilmaz, Y., Yonal, O., Deyneli, O., Celikel, C.A., Kalayci, C. and Duman, D.G. (2012) Effects of Sitagliptin in Diabetic Patients with Nonalcoholic Steatohepatitis. Acta Gastro-Enterologica Belgica, 75, 240-244. http://www.ncbi.nlm.nih.gov/pubmed/22870790

[49] Atıl, A. and Deniz, A. (2018) Could Be Serum Uric Acid a Risk Factor for Thrombosis and/or Uveitis in Behcet's Disease? Vascular, 26, 378-386. http://journals.sagepub.com/doi/10.1177/1708538117742831 https://doi.org/10.1177/1708538117742831

[50] Jensen, T., Niwa, K., Hisatome, I., Kanbay, M., Andres-Hernando, A., Roncal-Jimenez, C.A., et al. (2018) Increased Serum Uric Acid over Five Years İs a Risk Factor for Developing Fatty Liver. Scientific Reports, 8, Article No. 11735. http://www.nature.com/articles/s41598-018-30267-2 https://doi.org/10.1038/s41598-018-30267-2

[51] Yamagishi, S., Ishibashi, Y., Ojima, A, Sugiura, T. and Matsui, T. (2014) Linagliptin, a Xanthine-Based Dipeptidyl Peptidase-4 İnhibitor, Decreases Serum Uric Acid Levels in Type 2 Diabetic Patients Partly by Suppressing Xanthine Oxidase Activity. 
International Journal of Cardiology, 176, 550-552.

https://linkinghub.elsevier.com/retrieve/pii/S0167527314012157 https://doi.org/10.1016/j.ijcard.2014.07.023

[52] Moriya, C. and Satoh, H. (2016) Teneligliptin Decreases Uric Acid Levels by Reducing Xanthine Dehydrogenase Expression in White Adipose Tissue of Male Wistar Rats. Journal of Diabetes Research, 2016, Article ID: 3201534.

http://www.hindawi.com/journals/jdr/2016/3201534/ https://doi.org/10.1155/2016/3201534

[53] Shimodaira, M., Niwa, T., Nakajima, K. and Kobayashi, M. (2015) Beneficial Effects of Vildagliptin on Metabolic Parameters in Patients with Type 2 Diabetes. Endocrine, Metabolic \& Immune Disorders-Drug Targets, 15, 223-228.

http://www.ncbi.nlm.nih.gov/pubmed/25809193

https://doi.org/10.2174/1871530315666150324114149 